\title{
Ectomycorrhizal fungi inoculation alleviates simulated acid rain effects on soil ammonia oxidizers and denitrifiers in Masson pine forest
}

Yan Li, ${ }^{1,2 \#}$ Zhan Chen, ${ }^{3 \#}$ Ji-Zheng He, ${ }^{1,2,4}$ Qing Wang, ${ }^{1,2}$ Congcong Shen ${ }^{1,2}$ and Yuan $\mathrm{Ge}^{1,2 *}$

${ }^{1}$ State Key Laboratory of Urban and Regional Ecology, Research Center for Eco-Environmental Sciences, Chinese Academy of Sciences, Beijing 100085, China

${ }^{2}$ University of Chinese Academy of Sciences, Beijing 100049, China

${ }^{3}$ Institute of Forest Ecology, Environment and Protection, Chinese Academy of Forestry, Key Laboratory of Forest Ecology and Environment, State Forestry Administration, Beijing 100091, China

${ }^{4}$ Faculty of Veterinary and Agricultural Sciences, The University of Melbourne, Parkville, Victoria, Australia

${ }^{\#}$ Yan Li and Zhan Chen contributed equally to this work.

*For correspondence. E-mail: yuange@rcees.ac.cn; Tel.: (+86) 10 62913536; Fax: (+86) 1062923549

This is the author manuscript accepted for publication and has undergone full peer review but has not been through the copyediting, typesetting, pagination and proofreading process, which may lead to differences between this version and the Version of Record. Please cite this article as doi: 10.1111/1462-2920.14457

This article is protected by copyright. All rights reserved. 
Running title: EMF relieve acid rain effects on $\mathrm{N}$ cycle microbes 


\section{Originality-Significance Statement}

This paper firstly explored an interesting question regarding whether the effects of simulated acid rain on soil ammonia oxidizers and denitrifiers are modulated by plant-symbiotic ectomycorrhizal fungi in the forest ecosystem. Our results newly showed that inoculation with Pisolithus tinctorius under acid rain stress $(\mathrm{pH} 3.5)$ could improve soil substrate availability, and thus alleviate the deleterious effects of simulated acid rain on ammonia oxidizers and denitrifiers under the field condition. These novel findings are particularly significant, since they provide insights into how acid rain stress affects nitrogen cycling processes in forest soils, and how ectomycorrhizal fungi inoculation mediates these effects. 


\section{Summary}

Acid rain can cause severe effects on soil biota and nutrient biogeochemical cycles in the forest ecosystem, but how plant-symbiotic ectomycorrhizal fungi will modulate the effects remains unknown. Here we conducted a full factorial field experiment in a Masson pine forest by simultaneously controlling the acidity of the simulated rain ( $\mathrm{pH} 5.6$ versus $\mathrm{pH}$ 3.5) and the ectomycorrhizal fungi Pisolithus tinctorius inoculation (non-inoculation versus inoculation), to investigate the effects on ammonia oxidizers and denitrifiers. After ten months, compared to the control (rain $\mathrm{pH}$ 5.6, and non-inoculation), simulated acid rain ( $\mathrm{pH}$ 3.5) reduced soil nutrient content, decreased archaeal amoA gene abundance, and inhibited denitrification enzyme activity. Also, simulated acid rain altered the community compositions of all the examined functional genes (archaeal amoA, bacterial amoA, nirK, nirS, and nosZ). However, inoculation with ectomycorrhizal fungi under acid rain stress recovered soil nutrient content, archaeal amoA gene abundance, and denitrification enzyme activity to levels comparable to the control, suggesting that ectomycorrhizal fungi inoculation ameliorates simulated acid rain effects. Taken together, ectomycorrhizal fungi inoculation-potentially through improving soil substrate availability — could alleviate the deleterious effects of acid rain on nitrogen cycling microbes in forest soils. 


\section{Introduction}

Acid rain is a severe environmental problem in the world (Malakoff, 2010). Forest ecosystems are the principal receptors of acid rain. It has been predicted that acid deposition into forest ecosystems in 2040 would be about $46 \%$ higher than 1980s situation (Busch et al., 2001). Acid rain may lead to adverse effects on forest ecosystems, e.g., changing aboveground and belowground biomes (Hu et al., 2014a;

Wei et al., 2017), altering biogeochemical cycles (Ouyang et al., 2008), and disturbing ecosystem functions (Wang et al., 2010). Microbial mediated soil nitrogen cycling, one of the most critical biogeochemical processes, may influence many ecological characteristics of forest ecosystems including nutrient dynamics, plant growth (Levy-Booth et al., 2014), and greenhouse gas (e.g., $\mathrm{N}_{2} \mathrm{O}$ ) emission (Hu et al., 2015a). However, little is known about how acid rain will affect soil nitrogen cycling microbes and their associated functions.

Complete cycling of inorganic nitrogen in soil requires the interaction of nitrification and denitrification (Szukics et al., 2010). Ammonia oxidization, the oxidation of ammonia to nitrite, is the first and rate-limiting step of nitrification in soils. This process is driven by both ammonia-oxidizing bacteria (AOB) and ammonia-oxidizing archaea (AOA) (Könneke et al., 2005; Nicol and Schleper, 2006). Denitrification converts nitrate to dinitrogen gas $\left(\mathrm{N}_{2}\right)$ through sequential 
reduction, and is mainly mediated by denitrifiers with distinct reductases encoded by various genes (Zumft, 1997). Of these genes, nitrite reductase genes (nirK and nirS) and nitrous oxide reductase gene (nosZ) have usually been used as gene markers to analyze denitrifying community (Braker et al., 2000; Throbäck et al., 2004). Understanding the responses of nitrogen cycling microbes to acid rain is especially crucial for evaluating forest ecosystem functions.

Acid rain may affect soil nitrogen cycling microbes in ways that may either alter soil properties and substrate availability, or change the input of plant photosynthetic products into soils. For example, acid rain may affect soil nitrogen cycling microbes by adjusting soil $\mathrm{pH}$, since soil $\mathrm{pH}$ has been demonstrated to be an essential factor in influencing the abundance, community composition, and activity of soil nitrogen cycling microbes (Nicol et al., 2008; Liu et al., 2010). Also, acid rain may alter substrate availability of nitrogen cycling microbes due to its impact on nitrate leaching and plant nitrogen uptake, since soil nitrogen availability has been reported to affect soil ammonia oxidizers and denitrifiers (Levy-Booth et al., 2014). Moreover, dissolved organic carbon, the electron donor in denitrification process, could influence denitrifying communities (Attard et al., 2011). Therefore, acid rain may reduce the input of photosynthetic products into soils by inhibiting plant growth (Hu et al., 2014a), and thus affect nitrogen cycling microbes due to the decrease of 
soil available carbon.

Ectomycorrhizal fungi colonize roots to form symbioses with many tree species, acquiring photosynthates from the hosts and in turn enhancing plant uptake of soil nitrogen and other nutrients (Smith and Read, 2008). This common symbiotic relationship in forest ecosystems could improve the survival and growth of host plants under biotic and abiotic disturbances, e.g., pathogens, drought, and acid rain (Hagerberg et al., 2003; Gehring et al., 2017; Zampieri et al., 2017); and this association has been successfully used in reforestation programmes by inoculating seedlings with suitable ectomycorrhizal fungi (Futai et al., 2008). Moreover, previous studies provided evidence that ectomycorrhizal fungi can mobilize the nitrogen present in organic materials (e.g., plant litters), and thus increase the mobility of soil nitrogen (Courty et al., 2010; Rineau et al., 2013). Therefore, ectomycorrhizal fungi inoculation may alleviate or aggravate the effect of simulated acid rain on soil nitrogen cycling microbes, either by affecting carbon flow through plants into the soil, or by changing soil nitrogen availability. However, how the inoculation of ectomycorrhizal fungi will modulate the responses of nitrogen cycling microbes to simulated acid rain has yet to be investigated.

To explore the effects of simulated acid rain and ectomycorrhizal fungi inoculation on the abundance and community composition of microbes related to 
ammonia oxidization and denitrification, we conducted a field experiment in the soil planted with 2-year-old Masson pine seedlings (Pinus massoniana Lamb) in Southern China. The Masson pine is a widely planted coniferous species in Southern China, and its productivity is sensitive to acid precipitation (Wang et al., 2014). Moreover, Pisolithus tinctorius is considered as the most suitable ectomycorrhizal fungi for facilitating the survive of Pinus massoniana in nature (Li et al., 2014). The full factorial experimental design included two levels of the simulated rain (pH 5.6 versus $\mathrm{pH}$ 3.5) and the ectomycorrhizal fungi Pisolithus tinctorius inoculation (non-inoculation versus inoculation), respectively. Therefore, there were four treatments: rain pH 5.6 and ectomycorrhizal fungi non-inoculation (control, CK), rain $\mathrm{pH} 3.5$ and ectomycorrhizal fungi non-inoculation (simulated acid rain, SAR), rain $\mathrm{pH} 5.6$ and ectomycorrhizal fungi inoculation (EMF), and rain $\mathrm{pH} 3.5$ plus ectomycorrhizal fungi inoculation (SAR+EMF). After ten months, the functional genes associated with ammonia oxidization (archaeal $a m o A$ and bacterial $a m o A$ ) and denitrification (nirK, nirS, and nosZ) were analyzed using molecular approaches including quantitative PCR (qPCR), terminal restriction fragment length polymorphism (T-RFLP), cloning and sequencing. We also measured soil properties, potential nitrification rate (PNR), and denitrification enzyme activity (DEA). We hypothesized that: (1) simulated acid rain will reduce the abundance, and alter the 
community composition of soil ammonia oxidizers and denitrifiers by influencing soil properties; (2) ectomycorrhizal fungi inoculation can alleviate the detrimental effects of simulated acid rain on soil nitrogen cycling microbes by improving available nitrogen and carbon; and (3) the change in soil substrate availability will predict the responses of ammonia oxidizers and denitrifiers to the interactive impacts from simulated acid rain and ectomycorrhizal fungi inoculation.

\section{Results}

Effects of different treatments on soil properties

Two-way analysis of variance (ANOVA) revealed that simulated rain and ectomycorrhizal fungi inoculation interactively influenced soil properties including moisture, $\mathrm{pH}$, total carbon (TC), total nitrogen (TN), dissolved organic carbon (DOC), ammonium-N $\left(\mathrm{NH}_{4}{ }^{+}-\mathrm{N}\right)$, and nitrate- $\mathrm{N}\left(\mathrm{NO}_{3}{ }^{-}-\mathrm{N}\right)$ concentrations $(P<0.01$ for all, Supporting Information Table S1). Compared to CK, EMF treatment significantly decreased soil nitrogen and carbon contents (i.e., TC, TN, DOC, $\mathrm{NH}_{4}{ }^{+}-\mathrm{N}$, and $\mathrm{NO}_{3}{ }^{-}-\mathrm{N}$ concentrations, $P<0.01$ for all, Supporting Information Table S2); whereas compared to SAR treatment, SAR+EMF treatment significantly increased soil nitrogen and carbon contents $(P<0.01$ for all, Supporting Information

\section{Table S2).}


In comparison to CK, SAR treatment distinctly altered overall soil properties, as shown by the distinct separation of SAR treatment from the CK in the principal component analysis (PCA) plot of soil properties (Fig. 1). In detail, compared to CK, SAR treatment significantly reduced soil TC, TN, DOC, $\mathrm{NH}_{4}{ }^{+}-\mathrm{N}$, and $\mathrm{NO}_{3}{ }^{-} \mathrm{N}$ concentrations ( $P<0.01$ for all, Supporting Information Table S2). After ten months experiment, although all the treatments reduced soil $\mathrm{pH}(4.67-5.66)$ when compared to the initial soil $\mathrm{pH}$ (prior to the field experiment, 6.16), the decrease in SAR treatment was lower than in control (Supporting Information Table S2).

Moreover, the PCA plot visually showed that soil properties in the SAR+EMF treatment were similar to those in the CK (Fig. 1), indicating that the inoculation of ectomycorrhizal fungi alleviated the effect of simulated acid rain on soil properties. For example, in the SAR+EMF treatment most measured values of soil characteristics, e.g., soil TC, TN, DOC, and $\mathrm{NH}_{4}{ }^{+}-\mathrm{N}$, were similar to the observations in the CK, while significantly enhanced when compared to SAR treatment ( $P<0.01$ for all, Supporting Information Table S2). Additionally, $\mathrm{NO}_{3}{ }^{-} \mathrm{N}$ content significantly increased in the SAR+EMF treatment compared to CK $(P<$ 0.01, Supporting Information Table S2).

Changes in the abundance of ammonia oxidizers and denitrifiers in response to 
different treatments

Significant interactions between simulated rain and ectomycorrhizal fungi inoculation were found in affecting the abundances of AOA amoA and nosZ genes ( $P$ $<0.05$ for both, Supporting Information Table S3).

The copy numbers of AOA amoA gene varied from $3.05 \times 10^{7}$ to $6.84 \times 10^{7}$ copies $\mathrm{g}^{-1}$ soil across all treatments; while the AOB amoA gene copies were in the

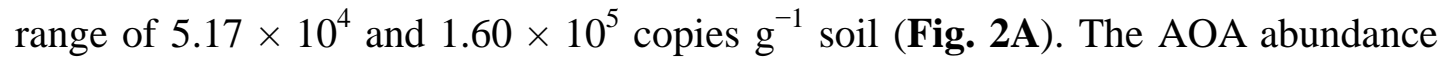
was consistently higher than AOB, with AOA: AOB ratios between 411.0 and 823.1. The AOA and AOB abundance and ratios were in the range of typical values reported by other studies (Adair and Schwartz, 2008; Bru et al., 2011). The AOA abundance significantly decreased in the SAR treatment compared to CK $(P<0.01)$, whereas recovered in the SAR+EMF treatment. In contrast, no significant difference in AOB abundance was observed among all treatments $(P=0.17)$.

The nirK and nirS genes were less abundant than nosZ gene: the copy numbers of nirK and nirS genes ranged from $1.82 \times 10^{6}$ to $2.90 \times 10^{6}$ and $7.82 \times 10^{5}$ to $2.12 \times$ $10^{6}$ copies $\mathrm{g}^{-1}$ soil, respectively; while nosZ gene varied from $4.89 \times 10^{6}$ to $8.98 \times$

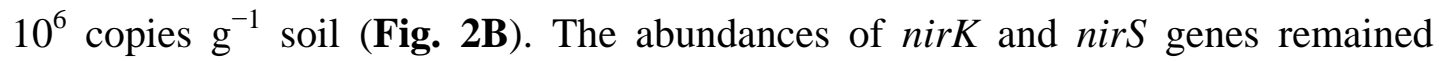
relatively stable in different treatments ( $P=0.096$, and $P=0.12$, respectively), whereas the abundance of nos $Z$ gene significantly increased in the SAR+EMF 
treatment compared to $\mathrm{CK}(P<0.05)$.

In addition, AOA abundance was significantly correlated with almost all measured soil characteristics except $\mathrm{NO}_{3}{ }^{-} \mathrm{N}$ by Pearson's correlation analysis (Supporting Information Fig. S1). For example, AOA amoA gene copy numbers negatively correlated with soil $\mathrm{pH}(R=-0.60, P<0.05)$, while positively correlated with soil moisture $(R=0.58, P<0.05)$, TC $(R=0.79, P<0.01)$, TN $(R=0.78, P<$ 0.01), DOC $(R=0.71, P<0.01)$, and $\mathrm{NH}_{4}{ }^{+} \mathrm{N}(R=0.77, P<0.01$, Supporting Information Fig. S1). The abundance of nosZ gene showed a significant positive correlation with only soil $\mathrm{NO}_{3}{ }^{-}-\mathrm{N}$ concentration $(R=0.70, P<0.05$, Supporting Information Fig. S1).

PNR ranged from 0.030 to $0.049 \mathrm{mg} \mathrm{NO}_{2}^{-}-\mathrm{N} \mathrm{kg}^{-1}$ soil h${ }^{-1}$ across all treatments (Fig. 3A). There was no significant difference of PNR between the treatments $(P=$ 0.35), but the highest PNR was recorded in the SAR treatment. Pearson's correlation analysis showed that PNR had a significant positive correlation with soil $\mathrm{pH}(R=$ 0.73, $P<0.01$, Supporting Information Fig. S1). The variation of DEA in different treatments differed from that of PNR (Fig. 3B). DEA was significantly and positively correlated with soil TC $(R=0.74, P<0.01)$, TN $(R=0.85, P<0.001)$, DOC $(R=0.78, P<0.01), \mathrm{NH}_{4}{ }^{+}-\mathrm{N}(R=0.77, P<0.01)$, and $\mathrm{NO}_{3}{ }^{-}-\mathrm{N}(R=0.83, P<$ 0.001). Therefore, the variation pattern of DEA in different treatments was similar to 
that of the above five soil characteristics. The potential assay is a method to estimate the biomass and functional potential of soil microbes involved in nitrogen cycling, due to its determination under assumed optimal conditions (Li et al., 2018). Thus, PNR and DEA were tested for correlations with the microbial abundance. The results showed that PNR had no significant correlation with the abundances of AOA and AOB. DEA showed a significant positive correlation with the abundance of nosZ gene ( $R=0.69, P<0.05$, Supporting Information Fig. S1).

Correlations of PNR and DEA with their substrate availability were also examined. Because ammonia $\left(\mathrm{NH}_{3}\right)$ is regarded as the actual substrate of ammonia oxidation in soils (He et al., 2012), correlation analysis was performed to examine the relationship between PNR and calculated $\mathrm{NH}_{3}$ content. The results of Pearson's correlation showed that PNR and DEA had significant positive correlations with their substrate availability ( $\mathrm{NH}_{3}$ and $\mathrm{NO}_{3}{ }^{-}-\mathrm{N}$ contents), respectively $(P<0.001$, and $P=0.001$, respectively, Fig. 3C and 3D). Besides, Spearman's rank correlation, which is a non-parametric statistical method independent of variables' distribution, was conducted to verify the above correlation. The results showed that PNR, and DEA still had a significant positive correlation with $\mathrm{NH}_{3}$ content $(R=0.706, P=$ $0.01)$, and $\mathrm{NO}_{3}{ }^{-} \mathrm{N}$ content $(R=0.853, P<0.001)$, respectively. 
Changes in the community composition of ammonia oxidizers and denitrifiers in response to different treatments

The principal coordinate analysis ( $\mathrm{PCoA})$ based on the Bray-Curtis distance matrices revealed that $\mathrm{AOA}$ and $\mathrm{AOB}$ community compositions in the SAR treatment were obviously different from those in the CK (Fig. 4B and 4D), and there were evident dissimilarities of denitrifying community compositions between different treatments (Fig. 4F, 4H, and $\mathbf{4 J}$ ). The comparisons of community dissimilarities between CK and other treatments were also used to explore whether ectomycorrhizal fungi inoculation could regulate the effect of simulated acid rain on microbial communities. The results revealed that community dissimilarities (Bray-Curtis distances) of AOA and nosZ-harboring denitrifiers between CK and SAR+EMF treatment significantly decreased relative to community dissimilarities between CK and SAR treatment $(P<0.01$ for both, Fig. 5A and 5B), while nirS-harboring denitrifiers showed the opposite trend $(P=0.001$, Fig. 5B). These results suggested that ectomycorrhizal fungi inoculation regulated the responses of microbial communities to simulated acid rain.

The T-RFLP profile of AOA amoA gene yielded 8 major terminal restriction fragments (T-RFs) across all the samples, of which T-RFs 166 and 205 bp were the two most dominant genotypes (Fig. 4A). Combined with cloning and sequencing 
analysis, 6 of the 8 major T-RFs could be assigned to phylogenetic affiliation. AOA sequences obtained by clone library were separated into 17 operational taxonomic units (OTUs) based on a similarity level of $97 \%$ and affiliated with the Nitrososphaera and Nitrosotalea clusters (Supporting Information Fig. S2). The relative abundance of T-RF 205 bp, mostly assigned to Nitrososphaera cluster, was distinctly changed by the treatments, as reflected by the significant decrease of relative abundance in the SAR and SAR+EMF treatment compared to CK $(P<0.05$, Fig. 4A), and the significant increase in the EMF treatment compared to CK $(P<$ 0.05). However, SAR+EMF treatment significantly increased its relative abundance when compared to SAR treatment $(P<0.05)$.

As for AOB amoA gene, seven major T-RFs were detected in all soil samples, of which T-RFs 251 and 272 bp were the two most dominant genotypes (Fig. 4C). AOB sequences obtained by clone library were separated into 9 OTUs and affiliated with Nitrosospira and Nitrosomonas (Supporting Information Fig. S3). T-RF 251 bp, assigned to cluster 4 and 9, had a higher relative abundance in the SAR treatment compared to CK ( $P=0.073$, Fig. 4C). T-RF 272 bp was assigned to cluster 3a, and its relative abundance significantly increased in the EMF treatment compared to CK $(P<0.05)$. Moreover, T-RF $88 \mathrm{bp}$, which was only detected in the SAR+EMF treatment, belonged to Nitrosomonas. 
In total, 16, 15, and 12 major distinct T-RFs were obtained for nirK, nirS, and nosZ genes respectively (Fig. 4E, 4G, and $\mathbf{4 I}$ ). The cloning library was constructed to detect the response of denitrifying microorganism to the different treatments on the genus level with nirK gene as the representative. NirK gene sequences were separated into 9 OTUs and predominantly assigned to Mesorhizobium and Rhodopseudomonas genus (Supporting Information Fig. S4). The genus Mesorhizobium was significantly changed in the SAR treatment relative to CK, with T-RFs 164 and 242 bp being not detected and T-RF 206 bp being observed under acid rain stress (Fig. 4E). However, T-RFs 164 and 242 bp recovered in the SAR+EMF treatment.

The correlations between microbial community composition and soil properties were examined by the partial Mantel test and redundancy analysis (RDA) (Table 1; Supporting Information Fig. S5). AOA community composition was significantly correlated with soil moisture content (Spearman's coefficient $R=0.40$, adjusted $P<$ 0.05, Table 1). In addition, soil $\mathrm{NO}_{3}{ }^{-} \mathrm{N}$ was an important edaphic property that had the highest correlations with community compositions of nirK-, nirS-, and nosZ-harboring denitrifiers $(R=0.48$, adjusted $P<0.01 ; R=0.67$, adjusted $P<0.01$; and $R=0.35$, adjusted $P<0.05$, respectively), while community compositions of nirK- and nirS-harboring denitrifiers were also significantly affected by soil TN $(R=$ 
0.37, adjusted $P<0.05 ; R=0.43$, adjusted $P<0.01$, respectively). Moreover, community composition of nirS-harboring denitrifiers was correlated with soil DOC $(R=0.33$, adjusted $P<0.05)$.

\section{Discussion}

We found that the inoculation of ectomycorrhizal fungi played a potential role in regulating the responses of ammonia oxidizers and denitrifiers to simulated acid rain through its effects on soil properties.

Ectomycorrhizal fungi inoculation modulated the responses of soil properties to simulated acid rain

This study suggested that ectomycorrhizal fungi inoculation modulated the responses of soil properties to simulated acid rain. This regulatory effect was demonstrated by the significant interactions between simulated rain and ectomycorrhizal fungi inoculation on all examined soil properties, as shown by the results of two-way ANOVA (Supporting Information Table S1). Our results confirmed the predicted reduction of soil nitrogen and carbon contents as a consequence of simulated acid rain. It was noted that the inoculation of ectomycorrhizal fungi under simulated acid rain was able to maintain soil nitrogen 
and carbon resources at the levels comparable to CK (Fig. 1; Supporting Information

\section{Table S2).}

In this study, although all the treatments reduced soil $\mathrm{pH}$ when compared to the initial soil $\mathrm{pH}$ prior to the field experiment, the decrease in SAR treatment was lower than in control. This seemingly contradictory result could be partially attributed to the higher ion exchange between rainwater and forest canopy in the SAR treatment. It has been reported that the $\mathrm{pH}$ value of precipitation could be modified after the interception by forest canopy (Zhang et al., 2006). Base cations (e.g., $\mathrm{Ca}^{2+}, \mathrm{Mg}^{2+}$, and $\mathrm{K}^{+}$) may be enriched in throughfall by canopy uptake of $\mathrm{H}^{+}$and leaching of base cations when acidic rainwater passes through the canopy (Lindberg et al., 1986; Shen et al., 2013), which may neutralize the acidity of precipitation and alleviate soil acidification to some extent (Stachurski and Zimka, 2002; Shen et al., 2013). To further test our explanation, we performed a separate experiment examining the effect of canopy exchange process on the acidity of precipitation (Supporting Information). It was demonstrated that the $\mathrm{pH}$ of throughfall in the SAR treatment (6.05) was significantly higher than the $\mathrm{pH}$ of throughfall in the CK (5.85) (t-test, $P$ $<0.05$, Supporting Information Fig. S6), which was attributed to the significantly increased canopy exchange process (uptake of $\mathrm{H}^{+}$and leaching of base cations) in the SAR treatment (Supporting Information Fig. S7). On the other hand, the loss of 
nutrient ions from foliage may directly affect plant growth (Lin et al., 2011), leading to the decreased release of plant photosynthetic carbon into soils. This could explain why soil total carbon was significantly reduced in the SAR treatment. As for nitrogen in the soil, nitrate leaching could contribute to the loss of total nitrogen under the simulated acid rain. Previous studies have demonstrated that the high concentrations of base cations or $\mathrm{H}^{+}$in throughfall may result in the loss of soil nitrogen through leaching (Blanco et al., 2012; Xu et al., 2015). Additionally, it was reported that acid rain could inhibit nitrogen mineralization, and thus reduce $\mathrm{NH}_{4}{ }^{+}-\mathrm{N}$ supply (Ouyang et al., 2008).

Soil properties in the SAR+EMF treatment were similar to those in the CK (Fig. 1; Supporting Information Table S2), suggesting that ectomycorrhizal fungi inoculation could alleviate the adverse effect of simulated acid rain on soil characteristics. Ectomycorrhizal fungi are known to facilitate the nutrient acquisition of their host plants (Blum et al., 2002; Smith and Read, 2008). This promoting effect of ectomycorrhizal fungi on plant growth could be explained by two possible mechanisms. Firstly, mycelium could extend into the soil and form a network of hyphae specialized in nutrient acquisition, contributing to an increase of the root absorbing area (Sebastiana et al., 2013). Secondly, ectomycorrhizal fungi could stimulate plant litter decomposition and soil mineral dissolution by producing 
enzymes or organic acids, and thus lead to the increase of available soil nitrogen and carbon (Lindahl et al., 2007; Sterkenburg et al., 2018). In addition, extensive hyphal networks of ectomycorrhizal fungi could effectively absorb nitrogen from the soil solution, and thus decrease soil inorganic nitrogen leaching under the simulated acid rain (Bahr et al., 2013). As a result, ectomycorrhizal fungi inoculation may improve available nitrogen and carbon for the microbial communities under acid rain stress.

Besides the effects on soil nitrogen and carbon contents induced by ectomycorrhizal fungi inoculation under acid rain stress, it should also be noted that soil moisture was significantly elevated in the SAR+EMF treatment compared to SAR treatment (Supporting Information Table S2). It was reported that soil organic matter could enhance soil water retention due to its positive influence on soil structure (Lal et al., 1997). Increasing organic matter increases soil porosity that could retain plant-available water and enhance water retention throughout the rooting zone (Huntington et al., 2006). Thus, the significant increase of soil total carbon in the SAR+EMF treatment may lead to enhanced soil water retention compared to SAR treatment. Moreover, ectomycorrhizal fungi could control water transfer to the plant (Muhsin and Zwiazeck, 2002; Courty et al., 2010), and thus retain water in plant roots. Therefore, ectomycorrhizal fungi may have an indirect effect on soil moisture availability. 
Furthermore, the interactions between simulated rain and ectomycorrhizal fungi inoculation in affecting soil properties were significant (Supporting Information Table S1). We hypothesized that the symbiotic relationship between plant roots and ectomycorrhizal fungi became stronger when seedlings were subjected to acid rain stress in this study, which is coincided with a previous study showing that mycorrhizal symbioses were more mutualistic with plants under stress (Johnson et al., 1997).

Effects of simulated acid rain and ectomycorrhizal fungi inoculation on AOA and $A O B$

In this study, simulated acid rain led to a dramatic decrease in available nitrogen and carbon concentrations in soil. Thus, a possible explanation for the impact of simulated acid rain on AOA abundance could be the obvious reduction of available soil nitrogen and carbon. Additionally, the significant increase in soil nitrogen and carbon by inoculating ectomycorrhizal fungi under acid rain stress might benefit the growth of AOA. However, AOB abundance was not markedly responsive to the different treatments (Fig. 2A), indicating that the ammonia oxidation might be mainly driven by AOA in the examined acidic soil. This result is line with previous studies performed in other acidic soils (Gubry-Rangin et al., 2010; Zhang et al., 
2012). By comparison, AOB was found to be functionally dominant in neutral and alkaline soils or soils receiving nitrogen inputs (Di et al., 2009; Jia and Conrad, 2009; Xia et al., 2011).

$\mathrm{NH}_{3}$ is generally regarded as the direct substrate of ammonia oxidation in soils (He et al., 2012). Therefore, correlation analysis was performed to examine the relationship between calculated $\mathrm{NH}_{3}$ content and the abundances of ammonia oxidizers. However, the highest $\mathrm{NH}_{3}$ content was recorded in the SAR treatment, while AOA abundance significantly decreased in this treatment (Supporting Information Fig. S8). This may occur if the growth of AOA is also inhibited by limited carbon resource under acid rain stress. It should be noted that AOA can directly use organic carbon and thus they may also be mixotrophs or heterotrophs (Chen et al., 2014; Qin et al., 2014). Tourna et al. (2011) demonstrated that the growth of Nitrososphaera viennensis could be stimulated by small additions of pyruvate, supporting that AOA can grow mixotrophically. Therefore, the significant decrease of soil available carbon content under acid rain stress was detrimental to the metabolism and growth of mixotrophic or heterotrophic AOA.

The direct comparisons of community dissimilarities by calculating Bray-Curtis distances showed that, in comparison to community dissimilarities of AOA between CK and SAR treatment, the dissimilarities between CK and SAR+EMF treatment 
significantly reduced (Fig. 5A). This result indicated ectomycorrhizal fungi inoculation could alleviate the effect of simulated acid rain on AOA community to some extent, which was similar to that observed for AOA abundance. The contrasting responses of ammonia oxidizers suggested that AOA were more sensitive to environmental changes, which were also proved by the results of correlation analysis between the functional gene abundance / microbial community composition and soil properties (Supporting Information Fig. S1; Table 1). The results of correlation analysis showed that the abundance and community composition of AOA were significantly correlated with soil properties, while there was no significant correlation detected between AOB and soil properties. The distinct responses of AOA and AOB were usually ascribed to their divergent affinity and sensitivity for ammonia substrate, and soil ammonia availability was considered as a direct factor leading to the difference of ammonia oxidizers (Verhamme et al., 2011). Therefore, the abundance and community composition of AOA, rather than AOB, responded sensitively to ammonia availability in ammonia-limited acidic soils, which could be attributed to the higher affinity of AOA for ammonia resources (Martens-Habbena et al., 2009; Verhamme et al., 2011).

In addition, the results from partial Mantel test and RDA showed that AOA community composition was highly responsive to change in soil moisture (Table 1; 
Supporting Information Fig. S5A), implying that soil water content in different treatments could regulate the shift in the AOA community composition. Gleeson et al. (2010) reported that AOA and AOB community compositions were markedly influenced by soil water availability in grassland soil. It was found that enhanced soil moisture could stimulate nitrogen mineralization, thereby influencing substrate availability of ammonia oxidation (Stark and Firestone, 1995). Moreover, increased soil water content could also accelerate the substrate diffusion to ammonia oxidizers (Hu et al., 2015b). Therefore, soil moisture might have an indirect effect on ammonia oxidizer communities by changing substrate availability and mobility.

There was no significant difference of PNR between the treatments (Fig. 3A), but the significant positive correlation was found between PNR and soil $\mathrm{pH}$ through correlation analysis (Supporting Information Fig. S1). The underlying mechanism for the effect of soil pH on PNR could be attributed to the pH-affected availability of ammonia substrate. PNR was found to have a significant positive correlation with calculated $\mathrm{NH}_{3}$ content in this study (Fig. 3C), indicating that the biomass of soil microbes involved in ammonia oxidation was highly responsive to change in substrate availability. However, PNR was not significantly correlated with the abundances of both AOA and AOB. This is in agreement with the result obtained by Zhang et al. (2017). Potential nitrification rate aims to determine the maximum 
capacity of soil microbes involved in ammonia oxidation to transform ammonia into nitrite under assumed optimal conditions ( $\mathrm{Li}$ et al., 2018). Therefore, a possible explanation for this result is that nitrification could also be mediated by heterotrophic bacteria and fungi in soils (Hu et al., 2016).

\section{Effects of simulated acid rain and ectomycorrhizal fungi inoculation on denitrifiers}

As for nirK gene, the abundance marginally differed among different treatments, with slightly lower values recorded in the SAR treatment (Fig. 2B). However, there was no remarkable reduction in the abundances of nirS and nosZ genes under acid rain stress compared to the control (Fig. 2B). The shifts of denitrifiers abundances in the SAR treatment suggest that nirK-harboring denitrifiers might be more sensitive to acid rain stress than nirS- and nosZ-harboring denitrifiers in forest soils. In addition, we found that nos $Z$ gene abundance was higher than the sum of nirK and nirS gene abundance across all treatments, suggesting a low emission of the greenhouse gas $\mathrm{N}_{2} \mathrm{O}$ in the tested soil, which could be mainly attributed to $\mathrm{N}_{2} \mathrm{O}$ reduction process mediated by nosZ-harboring denitrifiers. Moreover, nosZ gene abundance remarkably increased in the SAR+EMF treatment, most likely due to the dramatic increase in soil $\mathrm{NO}_{3}{ }^{-}-\mathrm{N}$ content by inoculating ectomycorrhizal fungi under acid rain stress. 
The comparisons of community dissimilarities revealed that community dissimilarities of nosZ-harboring denitrifiers between CK and SAR+EMF treatment significantly reduced compared to the dissimilarities between CK and SAR treatment, while nirS-harboring denitrifiers showed the opposite trend (Fig. 5B). These results indicated ectomycorrhizal fungi inoculation could modulate the effect of simulated acid rain on the denitrifying community. Furthermore, partial Mantel test showed that soil $\mathrm{NO}_{3}{ }^{-}-\mathrm{N}$ content was the primary edaphic property controlling the community compositions of denitrifiers harboring nirK, nirS, and nosZ genes (Table 1), suggesting that soil substrate availability might be directly linked to denitrifying community compositions. The results also showed that the shift of community composition of nirS-harboring denitrifiers was related to the dynamic changes of soil DOC which was the electron donor in denitrification process (Attard et al., 2011). Levy-Booth et al. (2014) reported that nirS gene was primarily influenced by soil carbon and more responsive to the increase of soil organic carbon than the nirK gene. Additionally, the community compositions of nirK- and nirS-harboring denitrifiers were affected by soil TN content, which is consistent with a previous study (Zeng et al., 2016). Thus, simulated acid rain and ectomycorrhizal fungi inoculation might indirectly alter denitrifiers community compositions by changing soil nitrogen and carbon contents, mainly due to the shift of $\mathrm{NO}_{3}{ }^{-}-\mathrm{N}$ content. 
There was a significant positive correlation between DEA and soil $\mathrm{NO}_{3}{ }^{-}-\mathrm{N}$ content (Fig. 3D), indicating that denitrification enzyme activity was strongly affected by substrate availability in the tested soil. In addition, our results showed that DEA was positively and significantly correlated with the copy numbers of nos $Z$ gene, which suggested that abundance of nosZ gene could predict soil denitrification enzyme activity (Petersen et al., 2012). In microcosm experiments, Salles et al. (2009) found that denitrifying communities with different species richness could result in various levels of denitrification, and community composition could exert an influence on community functioning. Therefore, denitrifiers harboring different functional genes contributed to denitrification function in the soil.

\section{Conclusions}

In conclusion, our study provides empirical evidence that the responses of ammonia oxidizers and denitrifiers to simulated acid rain were modulated by the inoculation of ectomycorrhizal fungi in forest soils as a result of the changes in soil properties, mainly due to the shift of substrate availability (including $\mathrm{NH}_{3}, \mathrm{NO}_{3}{ }^{-}-\mathrm{N}$, and organic carbon contents). This finding highlights that soil substrate availability may be a good indicator to predict the responses of ammonia oxidizers and denitrifiers to acid rain stress in forest ecosystems. 


\section{Experimental procedures}

\section{Field site description}

The experimental site is located in Changsha, Southern China $\left(28^{\circ} 26^{\prime} 9^{\prime \prime} \mathrm{N}\right.$, $\left.113^{\circ} 11^{\prime} 39^{\prime \prime} \mathrm{E}\right)$. Southern China is the third largest acid rain area, following Europe and North America (Rodhe et al., 2002). Changsha has a mean annual temperature of $17^{\circ} \mathrm{C}$ and mean annual precipitation of $1200-1400 \mathrm{~mm}$. In 2016, the frequency of acid rain $(\mathrm{pH}<5.6)$ in Changsha was $100 \%$, and the average rainwater $\mathrm{pH}$ was 4.8-5.4. The experimental plots were previously cultivated but had been fallow for 4 years prior to our study. The soil in this site is lateritic red soil. Before the start of treatment, soil $\mathrm{pH}$ and nutrients were measured as follows: a $\mathrm{pH}$ of 6.16 , organic matter content of $20.28 \mathrm{~g} \mathrm{~kg}^{-1}$, total nitrogen (N) of $1.30 \mathrm{~g} \mathrm{~kg}^{-1}$, available phosphorus (P) of $28.59 \mathrm{mg} \mathrm{kg}^{-1}$, and available potassium (K) of $31.5 \mathrm{mg} \mathrm{kg}^{-1}$.

\section{Experimental design and soil sampling}

The experimental design was full factorial, with two levels of the simulated rain (pH 5.6 versus $\mathrm{pH}$ 3.5) and the ectomycorrhizal fungi inoculation (non-inoculation versus inoculation), respectively. Because acid rain is usually defined as the rain with a pH less than 5.6 (Zhang et al., 2007), we chose pH 5.6 to represent the $\mathrm{pH}$ 
level of unpolluted rain, and $\mathrm{pH} 3.5$ to represent the $\mathrm{pH}$ level of simulated acid rain with further acidification. The experiment included four treatments: rain pH 5.6 and ectomycorrhizal fungi non-inoculation (control, CK), rain $\mathrm{pH} 3.5$ and ectomycorrhizal fungi non-inoculation (simulated acid rain, SAR), rain $\mathrm{pH} 5.6$ and ectomycorrhizal fungi inoculation (EMF), and rain pH 3.5 plus ectomycorrhizal fungi inoculation (SAR+EMF). Each treatment had three replicate plots (3 $\mathrm{m} \times 2 \mathrm{~m}$ for each plot) with about $1 \mathrm{~m}$ intervals between adjacent plots.

Because the acidification of rainwater is mainly caused by sulfates and nitrates in Southern China, acidic solutions were prepared by adding a mixture of $\mathrm{H}_{2} \mathrm{SO}_{4}$ and $\mathrm{HNO}_{3}$ (4:1 mole ratio) to the local underground water. The ectomycorrhizal strain was Pisolithus tinctorius isolated from Masson pine forest in Southern China. The granular inocula of Pisolithus tinctorius were produced by the Research Institute of Forestry, Chinese Academy of Forestry. Thirty seedlings of 2-year-old Masson pine (Pinus massoniana Lamb) were transplanted to each plot in March 2015. The inoculated seedlings were prepared by placing $50 \mathrm{~mL}$ granular inocula into the planting hole, to ensure the direct contact of mycelia with the roots. For the non-inoculated seedlings, the same procedures were performed except that the granular inocula were sterilized by autoclaving to eliminate viable Pisolithus tinctorius spores and hyphal fragments. To confirm that the ectomycorrhizal fungi 
inoculation in seedling roots under the field condition was successful, we determined ectomycorrhizal colonization in the non-inoculation and inoculation treatments based on the results of soil fungal community analyses (Supporting Information). The acidic solutions were applied in April 2015, by spraying the seedlings in each plot with 6.7 L prepared acidic solutions once a week.

Soil samples were collected in February 2016. In each plot, five soil cores (3.4 cm diameter, $20 \mathrm{~cm}$ depth) were collected and composited together as a single sample. After visible thick roots and leaves were removed, soil samples were transported to the laboratory on ice and passed through a $2 \mathrm{~mm}$ sieve, then divided into two parts. One was stored at $4^{\circ} \mathrm{C}$ for physicochemical analysis, and the other was stored at $-40^{\circ} \mathrm{C}$ before DNA extraction.

\section{Soil physicochemical analysis}

Soil $\mathrm{pH}$ was determined using an air-dried soil to $1 \mathrm{M} \mathrm{KCl}$ with a ratio of 1: 2.5 (wt: vol) by a Delta 320 pH-meter (Mettler-Toledo, Shanghai, China). Soil moisture content was measured by oven-drying the samples at $105^{\circ} \mathrm{C}$ for $24 \mathrm{~h}$. TC and TN were determined by a Vario III Element Analyzer (Elementar, Hanau, Germany). DOC was extracted from fresh soil by $0.5 \mathrm{M} \mathrm{K}_{2} \mathrm{SO}_{4}$ with a ratio of 1: 5 (wt: vol), then the filtered solution was determined by a Liqui II TOC Analyzer (Elementar, 
Hanau, Germany). Soil ammonium and nitrate were extracted from fresh soil by $2 \mathrm{M}$ $\mathrm{KCl}$ with a ratio of $1: 5$ (wt: vol), then the filtered solution was measured by an AA3 Continuous Flow Analyzer (Seal, Norderstedt, Germany).

$\mathrm{NH}_{3}$ is regarded as the actual substrate of ammonia oxidation in soils (He et al., 2012). Therefore, we calculated soil $\mathrm{NH}_{3}$ content according to soil $\mathrm{pH}$ and $\mathrm{NH}_{4}{ }^{+}$ content by equation (1). Equation (1) is based on the Henderson-Hasselbalch equation and assumes the acid dissociation constant (pKa) of 9.25 for the ionization of $\mathrm{NH}_{4}{ }^{+} / \mathrm{NH}_{3}$ (Norman and Barrett, 2016).

$$
\left[\mathrm{NH}_{3}\right]=\left[\mathrm{NH}_{4}{ }^{+}\right]\left[10^{(\text {soil } \mathrm{pH}-9.25)}\right]
$$

\section{PNR and DEA measurement}

PNR was measured with the chlorate inhibition method (Kurola et al., 2005).

Briefly, 5 g fresh soil was added to $20 \mathrm{~mL}$ of phosphate buffer solution (PBS, pH 7.4) with $1 \mathrm{mM}\left(\mathrm{NH}_{4}\right)_{2} \mathrm{SO}_{4}$. Potassium chlorate with a final concentration of $10 \mathrm{mM}$ was added to inhibit nitrite oxidation. The soil slurry was incubated in the dark at $25^{\circ} \mathrm{C}$ for $24 \mathrm{~h}$, and nitrite was extracted with $5 \mathrm{~mL}$ of $2 \mathrm{M} \mathrm{KCl}$ and measured at a wavelength of $540 \mathrm{~nm}$ by a SynergyH1 Microplate Reader (BioTek, Winooski, USA) (He et al., 2007).

DEA was measured using the acetylene inhibition technique (Smith and Tiedje, 
1979; Schinner et al., 1996). Fresh soil equivalent to $4 \mathrm{~g}$ dry soil was added to 100 $\mathrm{mL}$ sterile serum bottle. The total water holding of all spiked samples was adjusted to $13 \mathrm{~mL}$ with deionized water to make nitrate dissolve in water. Then the bottles were sealed with rubber stoppers and shaken at $25^{\circ} \mathrm{C}$ for 20 min to eliminate air from the soil. The headspace of each bottle was replaced by a $\mathrm{N}_{2}-\mathrm{C}_{2} \mathrm{H}_{2}$ mixture (90: 10, vol: vol) to provide anaerobic conditions and inhibit $\mathrm{N}_{2} \mathrm{O}$ reduction, and $8 \mathrm{~mL}$ of a solution containing $\mathrm{KNO}_{3}\left(56 \mathrm{mg} \mathrm{NO}_{3}^{-}-\mathrm{N} \mathrm{L}^{-1}\right)$ and glucose $\left(288 \mathrm{mg} \mathrm{C} \mathrm{L}{ }^{-1}\right)$ was added to each bottle. During the incubation at $25^{\circ} \mathrm{C}$, gas samples $(20 \mathrm{~mL})$ were taken at 0 and $6 \mathrm{~h}$ and then analyzed for $\mathrm{N}_{2} \mathrm{O}$ concentration using a 7890A Gas Chromatograph (Agilent, Wilmington, USA). The amount of $\mathrm{N}_{2} \mathrm{O}$ in the headspace and DEA were calculated as described by Schinner et al. (1996).

\section{DNA extraction}

Each soil DNA was extracted from $0.4 \mathrm{~g}$ of soil samples using the PowerSoil DNA Isolation Kit (MoBio, Carlsbad, USA) according to the manufacturer's instructions. The purity and quantity of extracted DNA were checked using a NanoDrop ND-1000 UV-Vis spectrophotometer (NanoDrop, Wilmington, USA) with $\mathrm{A} 260 / \mathrm{A} 280 \approx 1.8$ for all samples. The DNA solution was stored at $-40{ }^{\circ} \mathrm{C}$ until use. 
qPCR analysis

The quantification of ammonia oxidation microbes (AOA and AOB amoA genes) and denitrification microbes (nirK, nirS, and nosZ genes) was performed using an iCycler iQ5 Thermocycler (Bio-Rad, Hercules, USA) with two technical replicates for each sample. The $25 \mu \mathrm{L}$ reaction mixture contained $12.5 \mu \mathrm{L}$ SYBR Premix Ex Taq (TaKaRa, Dalian, China), $0.5 \mu \mathrm{L}$ of each primer $(10 \mu \mathrm{M})$, and $2 \mu \mathrm{L}$ of diluted template DNA (1-10 ng). Primers and reaction conditions of each target gene used for qPCR are shown in Supporting Information Table S4. Standard curves were generated using 10-fold serial dilutions of plasmid DNA. The amplification efficiency of qPCR assay ranged from $90 \%$ to $100 \%$ with $R^{2}>0.99$. After qPCR assays, the specificity of the amplification products was verified by the generation of melting curves and agarose gel electrophoresis.

\section{T-RFLP analysis}

For the T-RFLP analysis, PCR amplification was performed using the primers shown in Supporting Information Table S4, with each forward primer fluorescently labeled with FAM. The conditions for PCR reactions were the same as those for the qPCR assays. The $50 \mu \mathrm{L}$ reaction mixture contained $25 \mu \mathrm{L}$ Premix Ex Taq (TaKaRa, 
Dalian, China), $1 \mu \mathrm{L}$ of each primer $(10 \mu \mathrm{M})$, and $2 \mu \mathrm{L}$ of diluted template DNA (1-10 ng). The labeled PCR products were purified using the Gel Extraction Kit (Qiagen, Hilden, Germany), and then the purified PCR products were digested with restriction enzymes HpyCH4V for AOA amoA gene (Hu et al., 2015b), RsaI for AOB amoA gene (Wang et al., 2016), HaeIII for nirK gene (Guo et al., 2013), MspI for nirS gene (Guo et al., 2013), and MspI for nosZ gene (Hu et al., 2014b), respectively. The size and relative abundance of T-RFs were determined by a 3730xl DNA Analyzer (Applied Biosystems, Carlsbad, USA). T-RFLP profiles were analyzed using GeneMarker 2.2 (SoftGenetics, State College, USA). The relative abundance of individual T-RF was calculated as the peak area percentage of a specific T-RF in the whole T-RFLP profile. Only those T-RFs with a relative abundance $>1 \%$ and fragment lengths in the range of 50-500 bp were considered in the further analysis (Ge et al., 2016).

\section{Cloning and sequencing}

Clone libraries of ammonia oxidation genes (AOA and AOB amoA genes) and denitrification gene (nirK gene as a representative) were constructed to assign specific T-RFs to phylogenetic affiliation. PCR amplifications were performed using the same primers and reaction conditions as in the qPCR assays. PCR products from 
the same treatment (three replicates) were mixed. The pooled PCR products of each treatment were purified and ligated into the pMD19-T Simple Vector (TaKaRa, Dalian, China), and the resultant ligation products were transformed into Escherichia coli DH5 $\alpha$ competent cells (Tiangen, Beijing, China) following the manufacturer's instructions. Twenty positive clones were randomly selected from each treatment, then sequenced using a 3730xl DNA Analyzer (Applied Biosystems, Carlsbad, USA). OTUs were defined according to a similarity level of 97\% using QIIME (Caporaso et al., 2010). The representative sequences of OTUs and their reference sequences obtained by BLAST from GenBank were used to conduct the phylogenetic analysis. The phylogenetic tree was constructed within MEGA 5.1 using the neighbor-joining method based on the Kimura 2-parameter model with 1000 replicates to produce Bootstrap values (Hu et al., 2015b). The sequences retrieved in this study were submitted to GenBank. The accession numbers were MG543642 to MG543658 for AOA amoA gene, MG543659 to MG543667 for AOB amoA gene, and MG543668 to MG543676 for the nirK gene.

\section{Statistical analysis}

After data normality distribution and variance homogeneity were satisfied, two-way ANOVA was conducted to analyze the effects of simulated rain, 
ectomycorrhizal fungi inoculation and their interactions on soil physicochemical properties, PNR, DEA and functional gene abundances. One-way ANOVA in conjunction with a post-hoc least significant difference (LSD) test was used to determine the significant differences $(P<0.05)$ of the above parameters between treatments. The PCA was performed to visualize the overall differences in soil properties across treatments. Pearson's correlation analysis was conducted to examine the relationships between soil properties, PNR, DEA, and functional gene abundances. The PCoA based on the Bray-Curtis distance matrices was performed to compare the community composition of ammonia oxidizers and denitrifiers in different treatments. To explore whether ectomycorrhizal fungi inoculation could regulate the effect of simulated acid rain on microbial communities, the community dissimilarities between CK and other treatments were also tested by the direct comparisons of Bray-Curtis distances using one-way ANOVA with LSD test. The partial Mantel test with 9999 permutations was conducted to examine the Spearman's correlation between functional community composition and specific soil property. The original $P$ values of correlation analysis were adjusted for multiple comparisons using the Benjamini-Hochberg $(\mathrm{BH})$ method, to control the false discovery rate (Benjamini and Hochberg, 1995). The RDA was performed to explore the effects of soil properties on microbial community composition. Analyses were 
conducted using either R (http://www.r-project.org/), or SPSS (SPSS, Chicago, USA).

\section{Acknowledgements}

This work was supported by Chinese Academy of Sciences (XDB15020200, and Hundred Talents Program to Y. Ge), National Natural Science Foundation of China (41671254), and the Public Welfare Project of the National Scientific Research Institution (CAFRIFEEP201402).

\section{Conflict of Interest}

The authors declare that they have no conflicts of interest.

\section{References}

Adair, K.L., and Schwartz, E. (2008) Evidence that ammonia-oxidizing archaea are more abundant than ammonia-oxidizing bacteria in semiarid soils of northern Arizona, USA. Microb Ecol 56: 420-426.

Attard, E., Recous, S., Chabbi, A., De Berranger, C., Guillaumaud, N., Labreuche, J., et al. (2011) Soil environmental conditions rather than denitrifier abundance and diversity drive potential denitrification after changes in land uses. Glob Change Biol 17: 1975-1989. 
Bahr, A., Ellström, M., Akselsson, C., Ekblad, A., Mikusinska, A., and Wallander, H. (2013) Growth of ectomycorrhizal fungal mycelium along a Norway spruce forest nitrogen deposition gradient and its effect on nitrogen leakage. Soil Biol Biochem 59: 38-48.

Benjamini, Y., and Hochberg, Y. (1995) Controlling the false discovery rate: a practical and powerful approach to multiple testing. J R Stat Soc Ser B 57: 289-300.

Blanco, J.A., Wei, X., Jiang, H., Jie, C.Y., and Xin, Z.H. (2012) Impacts of enhanced nitrogen deposition and soil acidification on biomass production and nitrogen leaching in Chinese fir plantations. Can J Forest Res 42: 437-450.

Blum, J.D., Klaue, A., Nezat, C.A., Driscoll, C.T., Johnson, C.E., Siccama, T.G., et al. (2002) Mycorrhizal weathering of apatite as an important calcium source in base-poor forest ecosystems. Nature 417: 729-731.

Braker, G., Zhou, J., Wu, L., Devol, A.H., and Tiedje, J.M. (2000) Nitrite reductase genes (nirK and nirS) as functional markers to investigate diversity of denitrifying bacteria in Pacific Northwest marine sediment communities. Appl Environ Microbiol 66: 2096-2104.

Bru, D., Ramette, A., Saby, N.P.A., Dequiedt, S., Ranjard, L., Jolivet, C., et al. (2011) Determinants of the distribution of nitrogen-cycling microbial communities at 
the landscape scale. ISME J 5: 532.

Busch, G., Lammel, G., Beese, F.O., Feichter, J., Dentener, F.J., and Roelofs, G.J. (2001) Forest ecosystems and the changing patterns of nitrogen input and acid deposition today and in the future based on a scenario. Environ Sci Pollut Res 8: 95-102.

Caporaso, J.G., Kuczynski, J., Stombaugh, J., Bittinger, K., Bushman, F.D., Costello, E.K., et al. (2010) QIIME allows analysis of high-throughput community sequencing data. Nat Methods 7: 335-336.

Chen, Y.L., Hu, H.W., Han, H.Y., Du, Y., Wan, S.Q., Xu, Z.W., and Chen, B.D. (2014) Abundance and community structure of ammonia-oxidizing Archaea and Bacteria in response to fertilization and mowing in a temperate steppe in Inner Mongolia. FEMS Microbiol Ecol 89: 67-79.

Courty, P.E., Buée, M., Diedhiou, A.G., Frey-Klett, P., Le Tacon, F., Rineau, F., et al. (2010) The role of ectomycorrhizal communities in forest ecosystem processes: new perspectives and emerging concepts. Soil Biol Biochem 42: 679-698.

Di, H.J., Cameron, K.C., Shen, J.P., Winefield, C.S., O’Callaghan, M., Bowatte, S., and He, J.Z. (2009) Nitrification driven by bacteria and not archaea in nitrogen-rich grassland soils. Nat Geosci 2: 621-624.

Futai, K., Taniguchi, T., and Kataoka, R. (2008). Ectomycorrhizae and their 
importance in forest ecosystems. In Mycorrhizae: Sustainable Agriculture and Forestry. Siddiqui, Z.A., Akhtar, M.S., and Futai K. (eds). Dordrecht: Springer, pp. 241-285.

Ge, Y., Priester, J.H., Mortimer, M., Chang, C.H., Ji, Z., Schimel, J.P., and Holden, P.A. (2016) Long-term effects of multiwalled carbon nanotubes and graphene on microbial communities in dry soil. Environ Sci Technol 50: 3965-3974.

Gehring, C.A., Sthultz, C.M., Flores-Rentería, L., Whipple, A.V., and Whitham, T.G. (2017) Tree genetics defines fungal partner communities that may confer drought tolerance. Proc Natl Acad Sci USA 114: 11009-11011.

Gleeson, D.B., Müller, C., Banerjee, S., Ma, W., Siciliano, S.D., and Murphy, D.V. (2010) Response of ammonia oxidizing archaea and bacteria to changing water filled pore space. Soil Biol Biochem 42: 1888-1891.

Gubry-Rangin, C., Nicol, G.W., and Prosser, J.I. (2010) Archaea rather than bacteria control nitrification in two agricultural acidic soils. FEMS Microbiol Ecol 74: 566-574.

Guo, G.X., Deng, H., Qiao, M., Yao, H.Y., and Zhu, Y.G. (2013) Effect of long-term wastewater irrigation on potential denitrification and denitrifying communities in soils at the watershed scale. Environ Sci Technol 47: 3105-3113.

Hagerberg, D., Thelin, G., and Wallander, H. (2003) The production of 
ectomycorrhizal mycelium in forests: relation between forest nutrient status and local mineral sources. Plant Soil 252: 279-290.

He, J.Z., Shen, J.P., Zhang, L.M., Zhu, Y.G., Zheng, Y.M., Xu, M.G., and Di, H.J. (2007) Quantitative analyses of the abundance and composition of ammonia-oxidizing bacteria and ammonia-oxidizing archaea of a Chinese upland red soil under long-term fertilization practices. Environ Microbiol 9: 2364-2374.

He, J.Z., Hu, H.W., and Zhang, L.M. (2012) Current insights into the autotrophic thaumarchaeal ammonia oxidation in acidic soils. Soil Biol Biochem 55: 146-154.

Hu, W.J., Chen, J., Liu, T.W., Simon, M., Wang, W.H., Chen, J., et al. (2014a) Comparative proteomic analysis of differential responses of Pinus massoniana and Taxus wallichiana var. mairei to simulated acid rain. Int $J$ Mol Sci 15: 4333-4355.

Hu, Z., Meng, H., Shi, J.H., Bu, N.S., Fang, C.M., and Quan, Z.X. (2014b) Community size and composition of ammonia oxidizers and denitrifiers in an alluvial intertidal wetland ecosystem. Front Microbiol 5: 371.

Hu, H.W., Chen, D., and He, J.Z. (2015a) Microbial regulation of terrestrial nitrous oxide formation: understanding the biological pathways for prediction of emission rates. FEMS Microbiol Rev 39: 729-749. 
Hu, H.W., Macdonald, C.A., Trivedi, P., Holmes, B., Bodrossy, L., He, J.Z., and Singh, B.K. (2015b) Water addition regulates the metabolic activity of ammonia oxidizers responding to environmental perturbations in dry subhumid ecosystems. Environ Microbiol 17: 444-461.

Hu, H.W., Macdonald, C.A., Trivedi, P., Anderson, I.C., Zheng, Y., Holmes, B., et al. (2016) Effects of climate warming and elevated $\mathrm{CO}_{2}$ on autotrophic nitrification and nitrifiers in dryland ecosystems. Soil Biol Biochem 92: 1-15.

Huntington, T.G. (2006) Available water capacity and soil organic matter. Encyclopedia of Soil Science 1: 139-143.

Jia, Z., and Conrad, R. (2009) Bacteria rather than Archaea dominate microbial ammonia oxidation in an agricultural soil. Environ Microbiol 11: 1658-1671.

Johnson, N.C., Graham, J.H., and Smith, F.A. (1997) Functioning of mycorrhizal associations along the mutualism-parasitism continuum. New Phytol 135: $575-585$.

Könneke, M., Bernhard, A.E., de La Torre, J.R., Walker, C.B., Waterbury, J.B., and Stahl, D.A. (2005) Isolation of an autotrophic ammonia-oxidizing marine archaeon. Nature 437: 543-546.

Kurola, J., Salkinoja-Salonen, M., Aarnio, T., Hultman, J., and Romantschuk, M. (2005) Activity, diversity and population size of ammonia-oxidising bacteria in 
oil-contaminated landfarming soil. FEMS Microbiol Lett 250: 33-38.

Lal, R., Kimble, J.M., Follett, R.F., and Stewart, B.A. (1997) Soil Processes and the Carbon Cycle. Boca Raton, USA: CRC press.

Levy-Booth, D.J., Prescott, C.E., and Grayston, S.J. (2014) Microbial functional genes involved in nitrogen fixation, nitrification and denitrification in forest ecosystems. Soil Biol Biochem 75: 11-25.

Li, H., Peng, H., Wang, L., Wei, H., Li, N., and Jing, Q. (2014) Identification of fungal genes involved in the preinfection events between ectomycorrhizal association (Pisolithus tinctorius and Pinus massoniana). Mycol prog 13: 123-130.

Li, Y., Chapman, S.J., Nicol, G.W., and Yao, H. (2018) Nitrification and nitrifiers in acidic soils. Soil Biol Biochem 116: 290-301.

Lin, T.C., Hamburg, S.P., Hsia, Y.J., King, H.B., Wang, L.J., and Lin, K.C. (2011) Base cation leaching from the canopy of a subtropical rainforest in northeastern Taiwan. Can J Forest Res 31: 1156-1163.

Lindahl, B.D., Ihrmark, K., Boberg, J., Trumbore, S.E., Högberg, P., Stenlid, J., and Finlay, R.D. (2007) Spatial separation of litter decomposition and mycorrhizal nitrogen uptake in a boreal forest. New Phytol 173: 611-620.

Lindberg, S.E., Lovett, G.M., Richter, D.D., and Johnson, D.W. (1986) Atmospheric 
deposition and canopy interactions of major ions in a forest. Science 231: 141-145.

Liu, B., Mørkved, P.T., Frostegård, Å., and Bakken, L.R. (2010) Denitrification gene pools, transcription and kinetics of $\mathrm{NO}, \mathrm{N}_{2} \mathrm{O}$ and $\mathrm{N}_{2}$ production as affected by soil pH. FEMS Microbiol Ecol 72: 407-417.

Malakoff, D. (2010) Taking the sting out of acid rain. Science 330: 910-911.

Martens-Habbena, W., Berube, P.M., Urakawa, H., de La Torre, J.R., and Stahl, D.A. (2009) Ammonia oxidation kinetics determine niche separation of nitrifying Archaea and Bacteria. Nature 461: 976-979.

Muhsin, T.M., Zwiazeck, J.J. (2002) Ectomycorrhizas increase apoplastic water transport and root hydraulic conductivity in Ulmus Americana seedlings. New Phytol 153: 153-158.

Nicol, G.W., and Schleper, C. (2006) Ammonia-oxidising Crenarchaeota: important players in the nitrogen cycle? Trends Microbiol 14: 207-212.

Nicol, G.W., Leininger, S., Schleper, C., and Prosser, J.I. (2008) The influence of soil $\mathrm{pH}$ on the diversity, abundance and transcriptional activity of ammonia oxidizing archaea and bacteria. Environ Microbiol 10: 2966-2978.

Norman, J.S., and Barrett, J.E. (2016) Substrate availability drives spatial patterns in richness of ammonia-oxidizing bacteria and archaea in temperate forest soils. 
Soil Biol Biochem 94: 169-172.

Ouyang, X.J., Zhou, G.Y., Huang, Z.L., Liu, J.X., Zhang, D.Q., and Jiong, L.I. (2008) Effect of simulated acid rain on potential carbon and nitrogen mineralization in forest soils. Pedosphere 18: 503-514.

Petersen, D.G., Blazewicz, S.J., Firestone, M., Herman, D.J., Turetsky, M., and Waldrop, M. (2012) Abundance of microbial genes associated with nitrogen cycling as indices of biogeochemical process rates across a vegetation gradient in Alaska. Environ Microbiol 14: 993-1008.

Qin, W., Amin, S.A., Martens-Habbena, W., Walker, C.B., Urakawa, H., Devol, A.H., et al. (2014) Marine ammonia-oxidizing archaeal isolates display obligate mixotrophy and wide ecotypic variation. Proc Natl Acad Sci USA 111: 12504-12509.

Rineau, F., Shah, F., Smits, M.M., Persson, P., Johansson, T., Carleer, R., et al. (2013) Carbon availability triggers the decomposition of plant litter and assimilation of nitrogen by an ectomycorrhizal fungus. ISME J 7: 2010-2022.

Rodhe, H., Dentener, F., and Schulz, M. (2002) The global distribution of acidifying wet deposition. Environ Sci Technol 36: 4382-4388.

Salles, J.F., Poly, F., Schmid, B., and Roux, X.L. (2009) Community niche predicts the functioning of denitrifying bacterial assemblages. Ecology 90: 3324-3332. 
Schinner, F., Ohlinger, R., Kandeler, E., and Margesin, R. (1996) Methods in Soil Biology. Heidelberg, Germany: Springer.

Sebastiana, M., Pereira, V.T., Alcântara, A., Pais, M.S., and Silva, A.B. (2013) Ectomycorrhizal inoculation with Pisolithus tinctorius increases the performance of Quercus suber L. (cork oak) nursery and field seedlings. New Forest 44: 937-949.

Shen, W., Ren, H., Jenerette, G.D., Hui, D., and Ren, H. (2013) Atmospheric deposition and canopy exchange of anions and cations in two plantation forests under acid rain influence. Atmos Environ 64: 242-250.

Smith, M.S., and Tiedje, J.M. (1979) Phases of denitrification following oxygen depletion in soil. Soil Biol Biochem 11: 261-267.

Smith, S.E., and Read, D.J. (2008) Mycorrhizal Symbiosis, 3th edn. Cambridge, UK: Academic press.

Stachurski, A., and Zimka, J.R. (2002) Atmospheric deposition and ionic interactions within a beech canopy in the Karkonosze Mountains. Environ Pollut 118: 75-87.

Stark, J.M., and Firestone, M.K. (1995) Mechanisms for soil moisture effects on activity of nitrifying bacteria. Appl Environ Microbiol 61: 218-221.

Sterkenburg, E., Clemmensen, K.E., Ekblad, A., Finlay, R.D., and Lindahl, B.D. (2018) Contrasting effects of ectomycorrhizal fungi on early and late stage 
decomposition in a boreal forest. ISME J. Published online June 7, 2018. https://doi.org/10.1038/s41396-018-0181-2

Szukics, U., Abell, G.C.J., Hödl, V., Mitter, B., Sessitsch, A., Hackl, E., and Zechmeister-Boltenstern, S. (2010) Nitrifiers and denitrifiers respond rapidly to changed moisture and increasing temperature in a pristine forest soil. FEMS Microbiol Ecol 72: 395-406.

Throbäck, I.N., Enwall, K., Jarvis, Å., and Hallin, S. (2004) Reassessing PCR primers targeting nirS, nirK and nosZ genes for community surveys of denitrifying bacteria with DGGE. FEMS Microbiol Ecol 49: 401-417.

Tourna, M., Stieglmeier, M., Spang, A., Könneke, M., Schintlmeister, A., Urich, T., et al. (2011) Nitrososphaera viennensis, an ammonia oxidizing archaeon from soil. Proc Natl Acad Sci USA 108: 8420-8425.

Verhamme, D.T., Prosser, J.I., and Nicol, G.W. (2011) Ammonia concentration determines differential growth of ammonia-oxidizing archaea and bacteria in soil microcosms. ISME J 5: 1067-1071.

Wang, C., Guo, P., Han, G., Feng, X., Zhang, P., and Tian, X. (2010) Effect of simulated acid rain on the litter decomposition of Quercus acutissima and Pinus massoniana in forest soil microcosms and the relationship with soil enzyme activities. Sci Total Environ 408: 2706-2713. 
Wang, L., Chen, Z., Shang, H., Wang, J., and Zhang, P.Y. (2014) Impact of simulated acid rain on soil microbial community function in Masson pine seedlings. Electron J Biotechnol 17: 199-203.

Wang, Q., Zhang, L.M., Shen, J.P., Du, S., Han, L.L., and He, J.Z. (2016) Effects of dicyandiamide and acetylene on $\mathrm{N}_{2} \mathrm{O}$ emissions and ammonia oxidizers in a fluvo-aquic soil applied with urea. Environ Sci Pollut Res 23: 23023-23033.

Wei, H., Liu, W., Zhang, J., and Qin, Z. (2017) Effects of simulated acid rain on soil fauna community composition and their ecological niches. Environ Pollut 220: 460-468.

Xia, W., Zhang, C., Zeng, X., Feng, Y., Weng, J., Lin, X., et al. (2011) Autotrophic growth of nitrifying community in an agricultural soil. ISME J 5: 1226-1236.

Xu, H.Q., Zhang, J.E., Ouyang, Y., Lin, L., Quan, G.M., Zhao, B.L., and Yu, J.Y. (2015) Effects of simulated acid rain on microbial characteristics in a lateritic red soil. Environ Sci Pollut Res 22: 18260-18266.

Zampieri, E., Giordano, L., Lione, G., Vizzini, A., Sillo, F., Balestrini, R., and Gonthier, P. (2017) A nonnative and a native fungal plant pathogen similarly stimulate ectomycorrhizal development but are perceived differently by a fungal symbiont. New Phytol 213: 1836-1849.

Zeng, J., Lou, K., Zhang, C.J., Wang, J.T., Hu, H.W., Shen, J.P., et al. (2016) Primary 
succession of nitrogen cycling microbial communities along the deglaciated forelands of Tianshan Mountain, China. Front Microbiol 7: 1353.

Zhang, G., Zeng, G.M., Jiang, Y.M., Huang, G.H., Yao, J.M., Xiang, R.J., and Zhang, X.L. (2006) Seasonal ionic exchange in two-layer canopies and total deposition in a subtropical evergreen mixed forest in central-south China. Ann Forest Sci 63: 887-896.

Zhang, J.E., Ouyang, Y., and Ling, D.J. (2007) Impacts of simulated acid rain on cation leaching from the Latosol in south China. Chemosphere 67: 2131-2137.

Zhang, L.M., Hu, H.W., Shen, J.P., and He, J.Z. (2012) Ammonia-oxidizing archaea have more important role than ammonia-oxidizing bacteria in ammonia oxidation of strongly acidic soils. ISME J 6: 1032-1045.

Zhang, M.M., Alves, R.J.E., Zhang, D.D., Han, L.L., He, J.Z., and Zhang, L.M. (2017) Time-dependent shifts in populations and activity of bacterial and archaeal ammonia oxidizers in response to liming in acidic soils. Soil Biol Biochem 112: 77-89.

Zumft, W.G. (1997) Cell biology and molecular basis of denitrification. Microbiol Mol Biol Rev 61: 533-616. 


\section{Table and Figure legends}

Table 1 Correlations between the microbial community composition and soil properties using partial Mantel test with 9999 permutations.

Figure 1. Principal component analysis (PCA) to visualize the overall differences in soil properties (including soil moisture, $\mathrm{pH}$, total carbon, total nitrogen, dissolved organic carbon, ammonium- $\mathrm{N}$, and nitrate- $\mathrm{N}$ concentrations) across treatments. $\mathrm{CK}$ : rain $\mathrm{pH} 5.6$ and ectomycorrhizal fungi non-inoculation; SAR: rain $\mathrm{pH} 3.5$ and ectomycorrhizal fungi non-inoculation; EMF: rain pH 5.6 and ectomycorrhizal fungi inoculation; SAR+EMF: rain pH 3.5 plus ectomycorrhizal fungi inoculation.

Figure 2. Abundances of functional genes across treatments. (A) ammonia-oxidizing archaea (AOA) and ammonia-oxidizing bacteria (AOB) amoA genes abundances; (B) nirK, nirS, and nosZ genes abundances. Error bars represent standard errors of mean $(n=3) . * P<0.05, * * P<0.01$, as compared to CK. CK: rain $\mathrm{pH} 5.6$ and ectomycorrhizal fungi non-inoculation; SAR: rain pH 3.5 and ectomycorrhizal fungi non-inoculation; EMF: rain $\mathrm{pH} 5.6$ and ectomycorrhizal fungi inoculation; SAR+EMF: rain pH 3.5 plus ectomycorrhizal fungi inoculation.

Figure 3. Treatment and substrate availability effects on potential nitrification rate (RNR) and denitrification enzyme activity (DEA) across treatments. (A) PNR across treatments; (B) DEA across treatments. (C) Correlation between PNR and soil 
ammonia $\left(\mathrm{NH}_{3}\right)$ content; (D) Correlation between DEA and soil nitrate- $\mathrm{N}\left(\mathrm{NO}_{3}{ }^{-}-\mathrm{N}\right)$ content. Error bars represent standard errors of mean $(n=3){ }^{*} P<0.05$, as compared to CK. CK: rain pH 5.6 and ectomycorrhizal fungi non-inoculation; SAR: rain $\mathrm{pH} 3.5$ and ectomycorrhizal fungi non-inoculation; EMF: rain $\mathrm{pH} 5.6$ and ectomycorrhizal fungi inoculation; SAR+EMF: rain pH 3.5 plus ectomycorrhizal fungi inoculation.

Figure 4. Treatment effects on microbial communities characterized by terminal restriction fragment length polymorphism (T-RFLP). The T-RFLP profiles and principal coordinate analysis (PCoA) graphs of (A, B) ammonia-oxidizing archaea (AOA) amoA, (C, D) ammonia-oxidizing bacteria (AOB) amoA, (E, F) nirK, (G, H) nirS, and (I, J) nosZ genes across treatments. Error bars represent standard errors of mean $(n=3)$. The red $*$ means that the terminal restriction fragments (T-RFs) could be assigned to phylogenetic affiliation via cloning and sequencing analysis of AOA amoA, AOB amoA, and nirK genes. CK: rain $\mathrm{pH} 5.6$ and ectomycorrhizal fungi non-inoculation; SAR: rain pH 3.5 and ectomycorrhizal fungi non-inoculation; EMF: rain $\mathrm{pH} 5.6$ and ectomycorrhizal fungi inoculation; SAR+EMF: rain $\mathrm{pH} 3.5$ plus ectomycorrhizal fungi inoculation.

Figure 5. The comparisons of community dissimilarities (Bray-Curtis distances) between control and other treatments. (A) ammonia-oxidizing archaea (AOA) and 
ammonia-oxidizing bacteria (AOB); (B) nirK-, nirS-, and nosZ-harboring denitrifiers. Error bars represent standard errors of mean $(n=9)$. Different letters above the bars indicate a significant difference $(P<0.05)$. CK: rain pH 5.6 and ectomycorrhizal fungi non-inoculation; SAR: rain pH 3.5 and ectomycorrhizal fungi non-inoculation; EMF: rain pH 5.6 and ectomycorrhizal fungi inoculation; SAR+EMF: rain pH 3.5 plus ectomycorrhizal fungi inoculation. 
Table 1 Correlations between the microbial community composition and soil properties using partial Mantel test with 9999 permutations.

\begin{tabular}{cccccc}
\hline Soil properties & AOA & AOB & nirK & $n i r S$ & $n o s Z$ \\
\hline All soil properties & $\mathbf{0 . 3 9 * *}$ & 0.08 & $\mathbf{0 . 4 0 * *}$ & $\mathbf{0 . 4 7 * *}$ & $\mathbf{0 . 3 1}$ \\
Moisture & $\mathbf{0 . 4 0 *}$ & -0.03 & -0.10 & -0.16 & -0.11 \\
$\mathrm{pH}$ & 0.23 & -0.01 & -0.19 & -0.14 & -0.11 \\
$\mathrm{TC}$ & 0.15 & -0.14 & 0.10 & -0.17 & 0.23 \\
$\mathrm{TN}$ & -0.21 & 0.14 & $\mathbf{0 . 3 7 *}$ & $\mathbf{0 . 4 3} * *$ & 0.18 \\
$\mathrm{DOC}$ & -0.16 & 0.12 & 0.24 & $\mathbf{0 . 3 3 *}$ & 0.16 \\
$\mathrm{NH}_{4}{ }^{+}-\mathrm{N}$ & -0.13 & -0.16 & 0.04 & -0.18 & 0.12 \\
$\mathrm{NO}_{3}{ }^{-}-\mathrm{N}$ & -0.05 & 0.24 & $\mathbf{0 . 4 8 * *}$ & $\mathbf{0 . 6 7 * *}$ & $\mathbf{0 . 3 5 *}$ \\
\hline
\end{tabular}

The values in the table are the Spearman's correlation coefficients.

Significance levels (adjusted $P$ ): * adjusted $P<0.05$, ** adjusted $P<0.01$.

TC: total carbon; TN: total nitrogen; DOC: dissolved organic carbon; $\mathrm{NH}_{4}{ }^{+} \mathrm{N}$ : ammonium-N; $\mathrm{NO}_{3}{ }^{-}-\mathrm{N}$ : nitrate-N; AOA: ammonia-oxidizing archaea; AOB: ammonia-oxidizing bacteria; nirK, nirS, and nosZ: denitrifiers harboring nirK, nirS, and nosZ genes, respectively. 


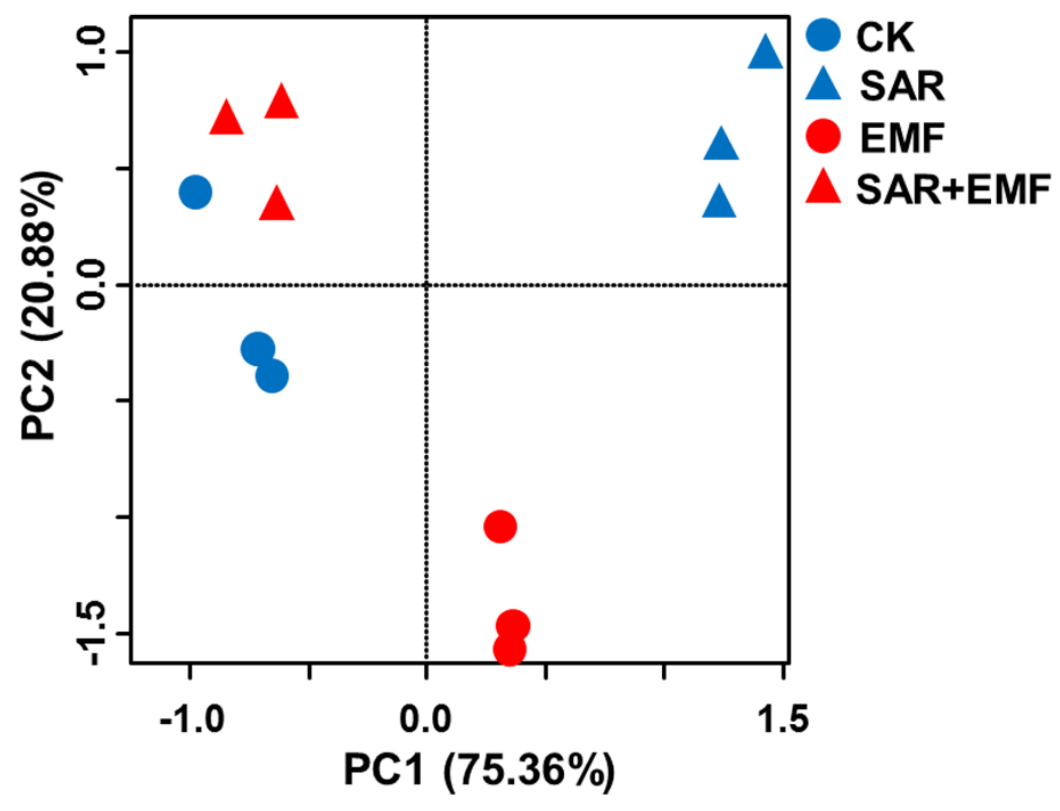

Fig. 1. Principal component analysis (PCA) to visualize the overall differences in soil properties (including soil moisture, $\mathrm{pH}$, total carbon, total nitrogen, dissolved organic carbon, ammonium-N, and nitrate-N concentrations) across treatments. CK: rain $\mathrm{pH} 5.6$ and ectomycorrhizal fungi non-inoculation; SAR: rain pH 3.5 and ectomycorrhizal fungi non-inoculation; EMF: rain pH 5.6 and ectomycorrhizal fungi inoculation; SAR+EMF: rain $\mathrm{pH} 3.5$ plus ectomycorrhizal fungi inoculation. 
(A)

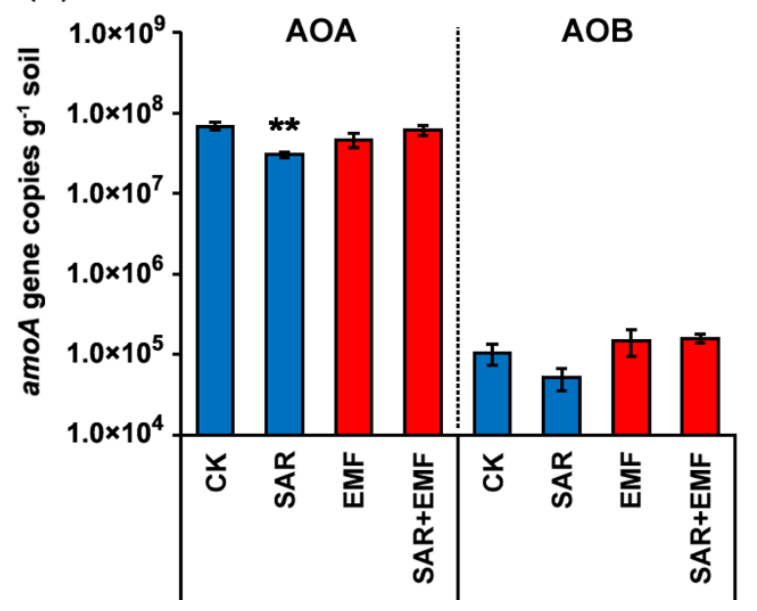

(B)

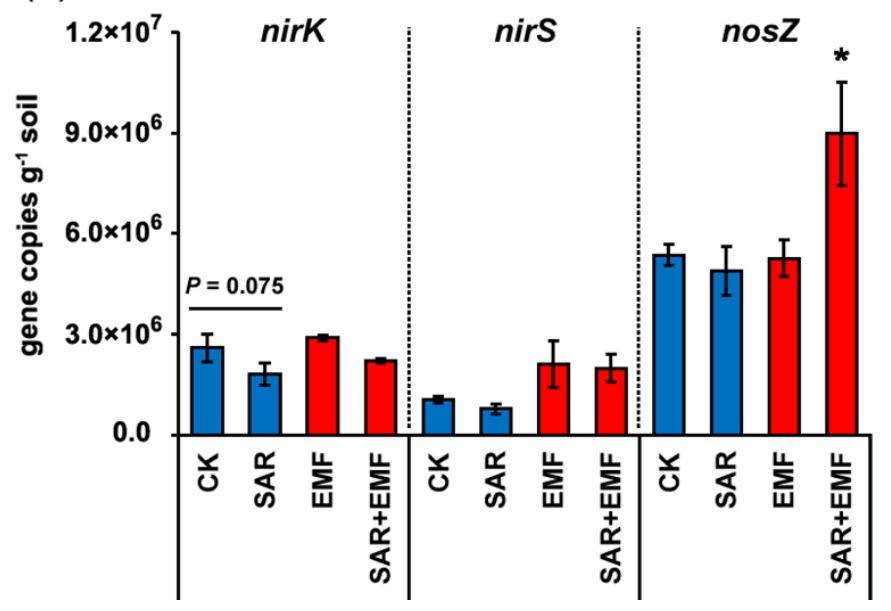

Fig. 2. Abundances of functional genes across treatments. (A) ammonia-oxidizing archaea (AOA) and ammonia-oxidizing bacteria (AOB) amoA genes abundances; (B) nirK, nirS, and nosZ genes abundances. Error bars represent standard errors of mean $(n=3)$. ${ }^{*} P<0.05$, ${ }^{* *} P<0.01$, as compared to CK. CK: rain pH 5.6 and ectomycorrhizal fungi non-inoculation; SAR: rain pH 3.5 and ectomycorrhizal fungi non-inoculation; EMF: rain pH 5.6 and ectomycorrhizal fungi inoculation; SAR+EMF: rain pH 3.5 plus ectomycorrhizal fungi inoculation. 
(A)

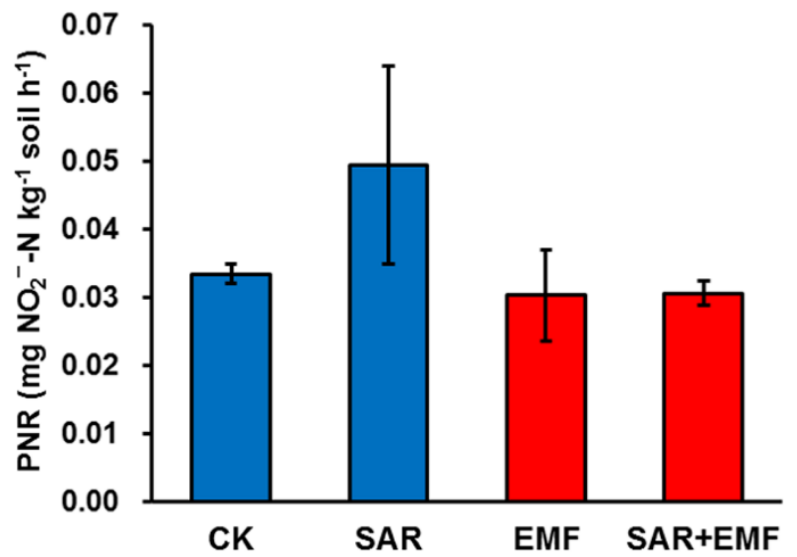

(C)

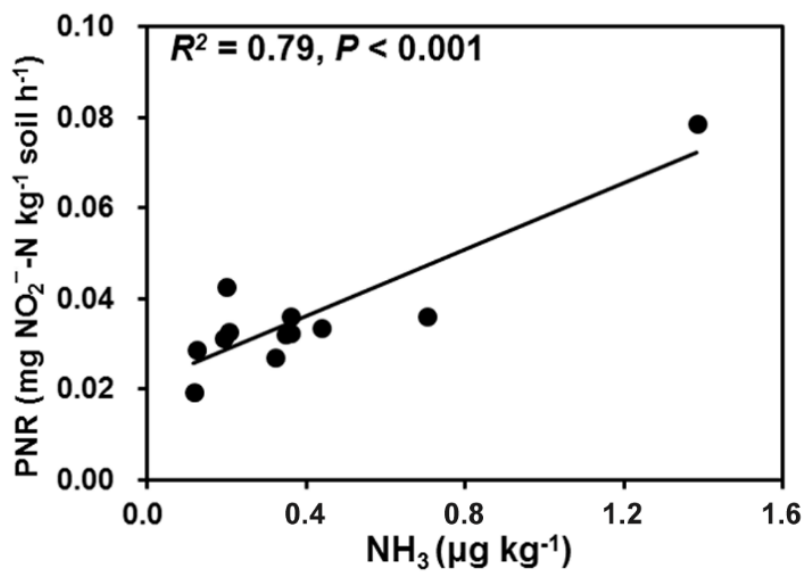

(B)

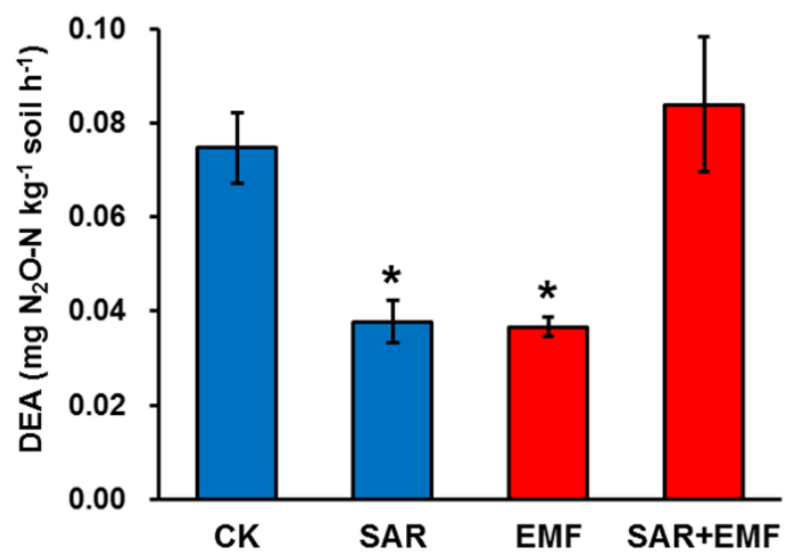

(D)

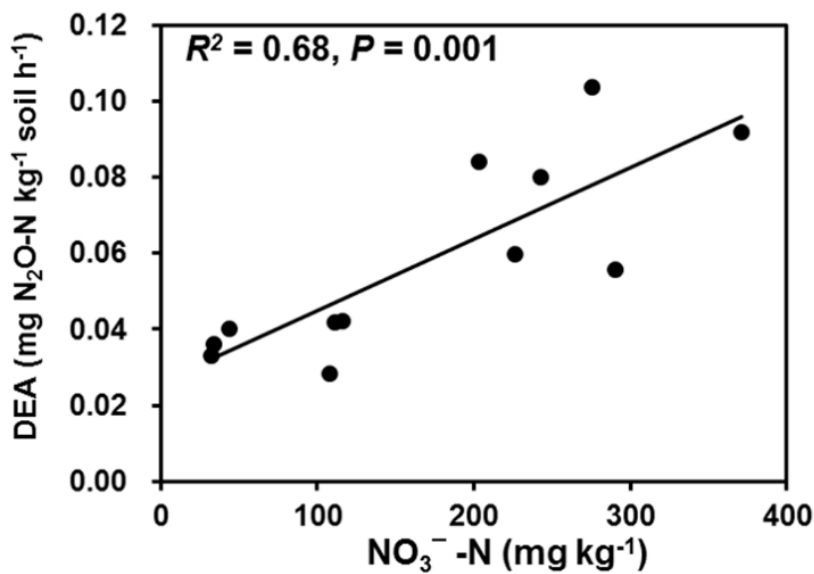

Fig. 3. Treatment and substrate availability effects on potential nitrification rate (RNR) and denitrification enzyme activity (DEA) across treatments. (A) PNR across treatments; (B) DEA across treatments. (C) Correlation between PNR and soil ammonia $\left(\mathrm{NH}_{3}\right)$ content; (D) Correlation between DEA and soil nitrate-N $\left(\mathrm{NO}_{3}{ }^{-}-\mathrm{N}\right)$ content. Error bars represent standard errors of mean $(n$ $=3) .{ }^{*} P<0.05$, as compared to $\mathrm{CK}$. CK: rain $\mathrm{pH} 5.6$ and ectomycorrhizal fungi non-inoculation; SAR: rain $\mathrm{pH} 3.5$ and ectomycorrhizal fungi non-inoculation; EMF: rain $\mathrm{pH} 5.6$ and ectomycorrhizal fungi inoculation; SAR+EMF: rain pH 3.5 plus ectomycorrhizal fungi inoculation. 

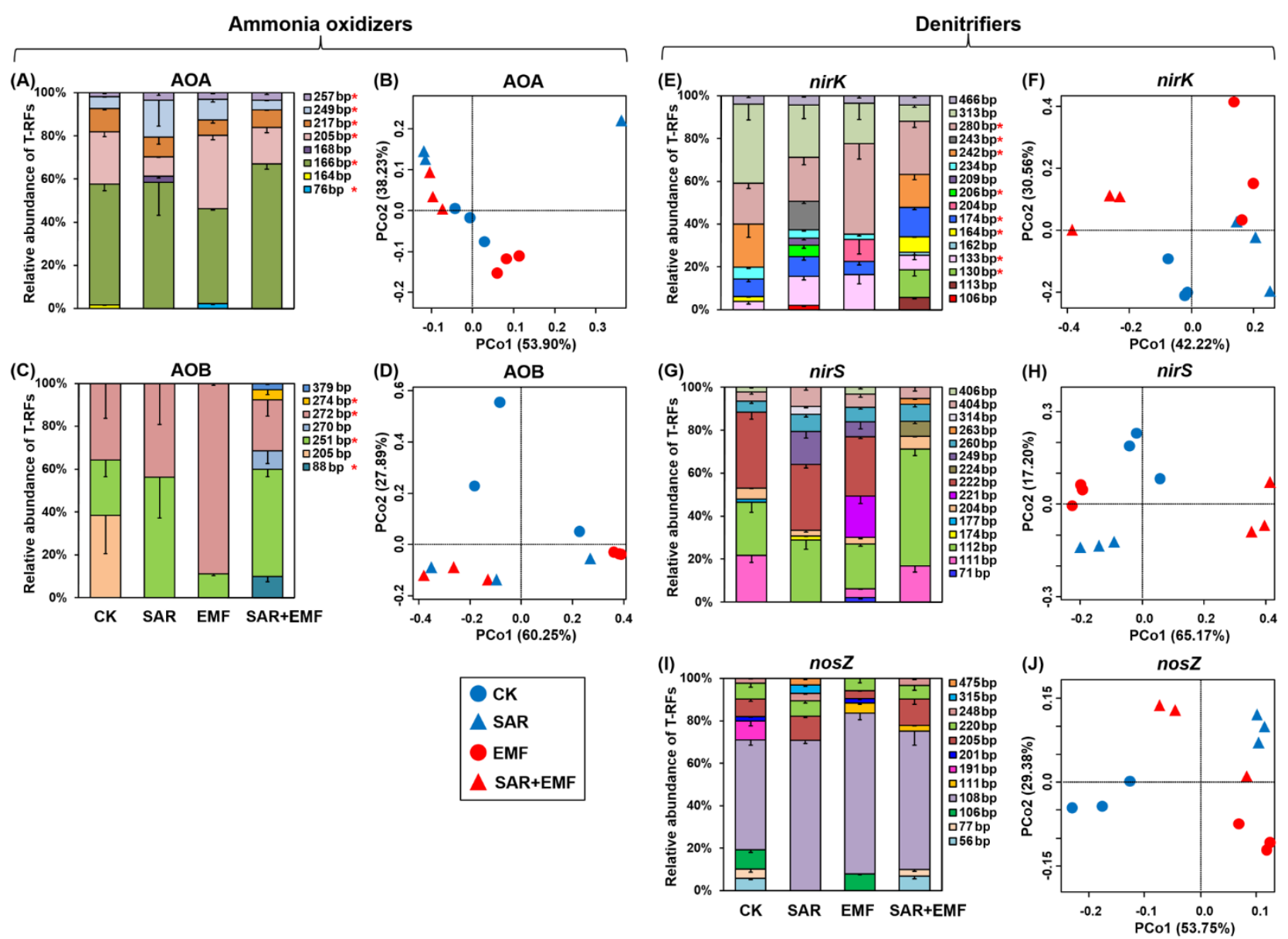

Fig. 4. Treatment effects on microbial communities characterized by terminal restriction fragment length polymorphism (T-RFLP). The T-RFLP profiles and principal coordinate analysis (PCoA) graphs of (A, B) ammonia-oxidizing archaea (AOA) amoA, (C, D) ammonia-oxidizing bacteria (AOB) amoA, (E, F) nirK, (G, H) nirS, and (I, J) nosZ genes across treatments. Error bars represent standard errors of mean $(n=3)$. The red $*$ means that the terminal restriction fragments (T-RFs) could be assigned to phylogenetic affiliation via cloning and sequencing analysis of AOA amoA, AOB amoA, and nirK genes. CK: rain pH 5.6 and ectomycorrhizal fungi non-inoculation; SAR: rain pH 3.5 and ectomycorrhizal fungi non-inoculation; EMF: rain pH 5.6 and ectomycorrhizal fungi 
inoculation; SAR+EMF: rain pH 3.5 plus ectomycorrhizal fungi inoculation. 
(A)

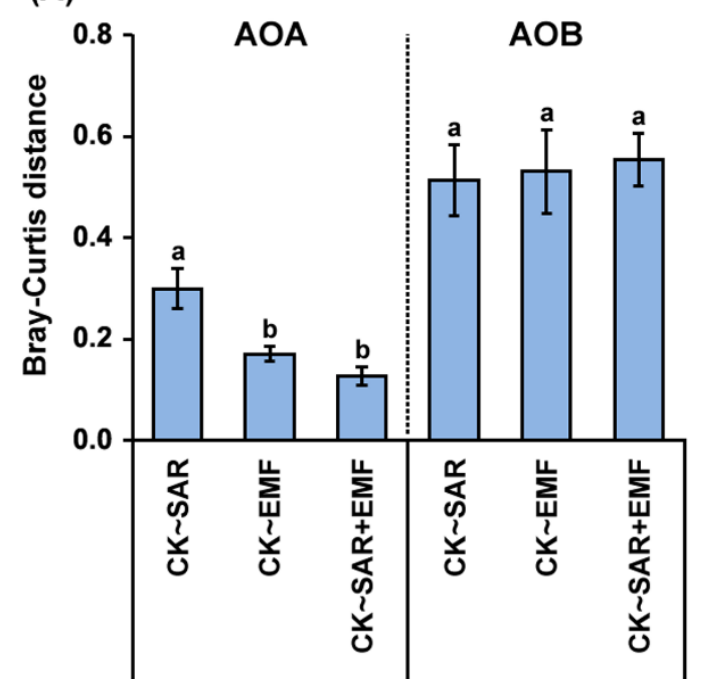

(B)

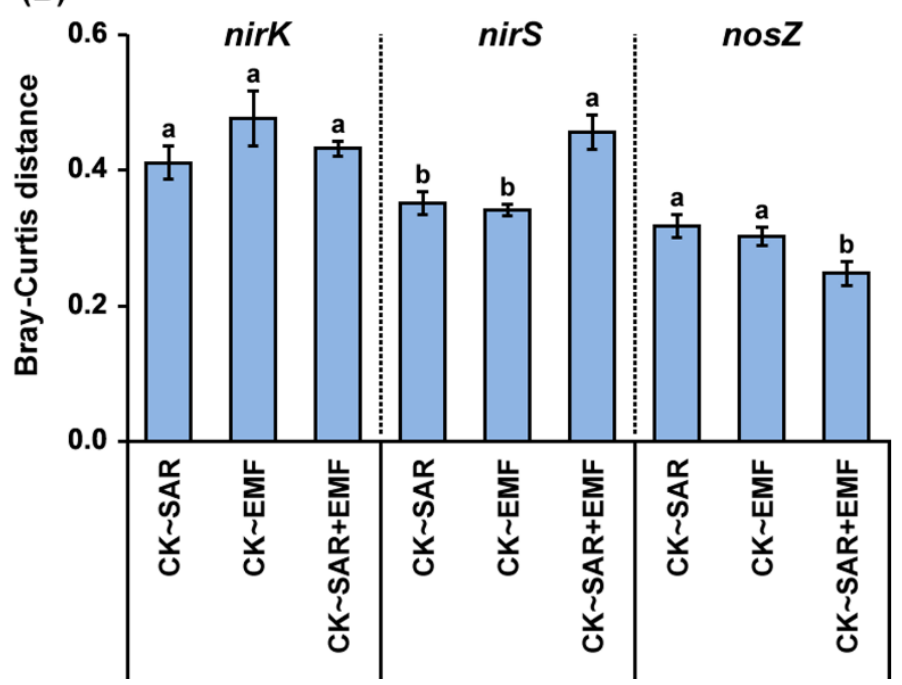

Fig. 5. The comparisons of community dissimilarities (Bray-Curtis distances) between control and other treatments. (A) ammonia-oxidizing archaea (AOA) and ammonia-oxidizing bacteria (AOB); (B) nirK-, nirS-, and nosZ-harboring denitrifiers. Error bars represent standard errors of mean $(n=$ 9). Different letters above the bars indicate a significant difference $(P<0.05)$. CK: rain $\mathrm{pH} 5.6$ and ectomycorrhizal fungi non-inoculation; SAR: rain $\mathrm{pH} 3.5$ and ectomycorrhizal fungi non-inoculation; EMF: rain pH 5.6 and ectomycorrhizal fungi inoculation; SAR+EMF: rain pH 3.5 plus ectomycorrhizal fungi inoculation. 


\section{University Library}

\section{$\bullet-\underset{A C C E S S}{M}$ I N E V A}

\section{A gateway to Melbourne's research publications}

Minerva Access is the Institutional Repository of The University of Melbourne

Author/s:

Li, Y;Chen, Z;He, J-Z;Wang, Q;Shen, C;Ge, Y

Title:

Ectomycorrhizal fungi inoculation alleviates simulated acid rain effects on soil ammonia oxidizers and denitrifiers in Masson pine forest

Date:

2019-01-01

\section{Citation:}

Li, Y., Chen, Z., He, J. -Z., Wang, Q., Shen, C. \& Ge, Y. (2019). Ectomycorrhizal fungi inoculation alleviates simulated acid rain effects on soil ammonia oxidizers and denitrifiers in Masson pine forest. ENVIRONMENTAL MICROBIOLOGY, 21 (1), pp.299-313. https:// doi.org/10.1111/1462-2920.14457.

Persistent Link:

http://hdl.handle.net/11343/284746 